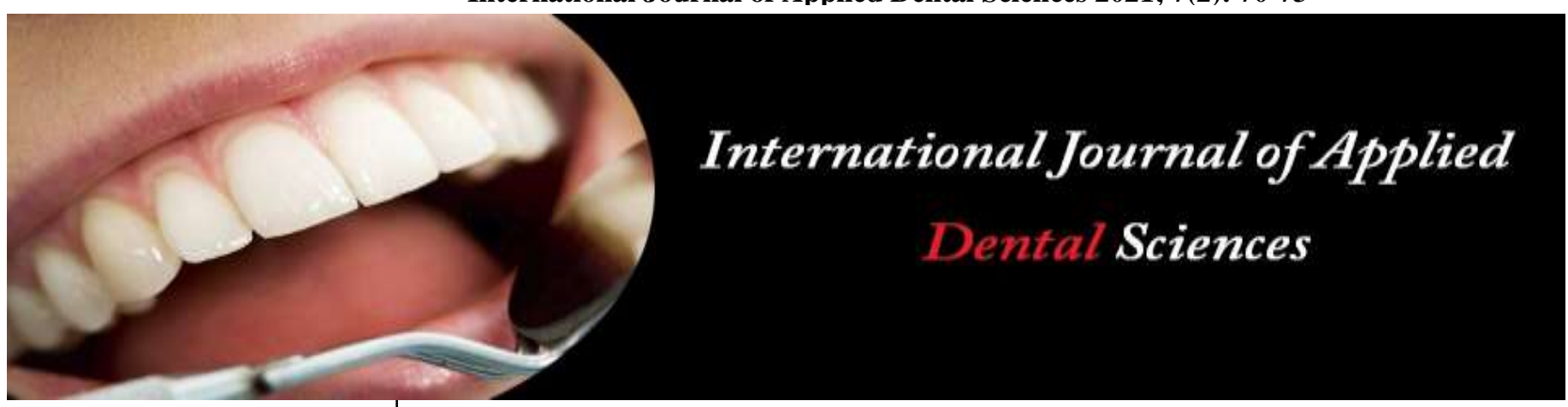

ISSN Print: 2394-7489

ISSN Online: 2394-7497

IJADS 2021; 7(2): 70-73

(C) 2021 IJADS

www.oraljournal.com

Received: 03-01-2021

Accepted: 22-02-2021

\section{Ishita Dubey}

$3^{\text {rd }}$ Year Post Graduate Student,

Department of Orthodontics and

Dentofacial Orthopaedics,

Subharti Dental College, Swami

Vivekanand Subharti

University, Meerut, Uttar

Pradesh, India

\section{Amit Khera}

Associate Professor, Department of Orthodontics and Dentofacial Orthopaedics, Subharti Dental

College, Swami Vivekanand

Subharti University, Meerut,

Uttar Pradesh, India

\section{Pradeep Raghav}

Professor and Head, Department of Orthodontics and Dentofacial Orthopaedics, Subharti Dental College, Swami Vivekanand Subharti University, Meerut, Uttar Pradesh, India
Corresponding Author: Ishita Dubey

$3^{\text {rd }}$ Year Post Graduate Student,

Department of Orthodontics and

Dentofacial Orthopaedics,

Subharti Dental College, Swami

Vivekanand Subharti

University, Meerut, Uttar

Pradesh, India

\section{Role of vibrations in orthodontics}

\author{
Ishita Dubey, Amit Khera and Pradeep Raghav
}

DOI: https://doi.org/10.22271/oral.2021.v7.i2b.1190

\section{Abstract}

Orthodontists from a long time have been trying different methods for reducing the treatment time. Vibratory stimulation has been advocated as a possible adjunct to orthodontic appliances to increase the rate of tooth movement and also decrease the pain associated with orthodontic treatment. This article summarises the different types of vibratory appliances used in orthodontics as well as role of these appliances in accelerating tooth movement and reducing pain.

Keywords: Vibration, orthoodontic tooth movement, bone remodelling

\section{Introduction}

Vibration, otherwise known as high frequency, low magnitude stimulation, is defined as a mechanical stimulus characterised by an oscillatory motion ${ }^{[1]}$. Vibration therapy has been used in health care since the 1800s. The first electro-mechanical vibrator was a device called a "percuteur" invented by British physician Joseph Mortimer Granville in the late 1870s or early 1880 s $^{[2]}$. Granville thought that vibration powered the human nervous system, and he developed the percuteur as a medical device for stimulating ailing nerves. Vibration therapy has been successful in improving or maintaining bone and muscle mass in cases such as mobility impaired patients, decreased bone density and in surgical healing. The first known attempt to apply pulsating forces to the dentition in an orthodontic application with humans was likely conducted by Everett Shapiro et al. ${ }^{[3]}$ Vibration in orthodontics has been applied with the main aim of increasing the rate of orthodontic tooth movement by accelerating the periodontal and bony tissue modelling and remodelling processes. This has the benefit of decreasing the duration that a patient has fixed appliances on their teeth.

\section{Types of Vibration devices used in Orthodontics}

\section{Accele Dent device}

The most common, commercially available, vibration device for orthodontic treatment is Accele Dent manufactured by Ortho Accel Technologies, Bellaire, Texas, USA. AcceleDent is a Class II FDA cleared device that uses soft pulse technology and cyclic forces to accelerate the movement of teeth. This device delivers a vibrational frequency of $30 \mathrm{~Hz}$ and requires 20 minutes per day user wear time ${ }^{[1]}$.

Several early studies on the Accele Dent device seemed to demonstrate higher rates of OTM than the established norms. However, there are other more recent studies that have failed to establish the advantages of the same therapy. A study by Woodhouse et al. ${ }^{[4]}$ analyzed the Accele Dent device to demonstrate its effect on OTM in extraction cases. They found that the supplemental vibrational force did not significantly increase rates of orthodontic alignment with a fixed appliance. Another comprehensive report on vibration therapy by Yadav et al. ${ }^{[5]}$ concluded that low frequency mechanical vibration using Accele Dent had no significant effect in accelerating tooth movement. Alikhani et al ${ }^{[6]}$ found a statistically higher rate of alveolar bone formation at higher frequencies, with a $5 \mathrm{~min} /$ day application. 


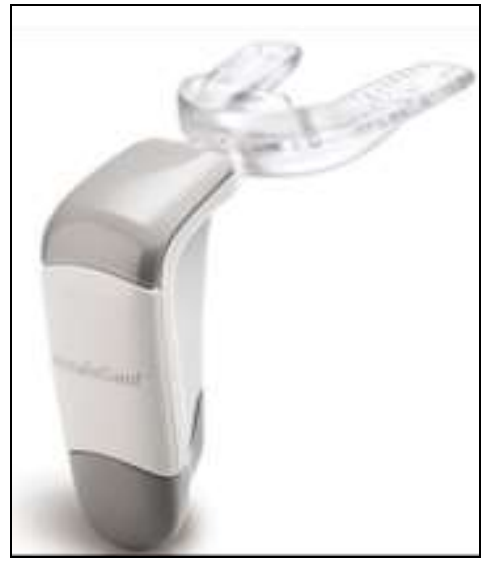

Fig 1: Accele Dent device

\section{Tooth masseuse}

It is a vibration device manufactured by the Good Vibrations, Raintree Essix, Inc., New Orleans, USA. It applies a vibrational frequency of $111 \mathrm{~Hz}$ and $0.06 \mathrm{~N}(\sim 6.1 \mathrm{~g})$ for 20 minutes per day, or more if desired ${ }^{[7]}$.

An RCT conducted by Miles et al. ${ }^{[7]}$ on the use of Tooth masseuse device demonstrated no advantage in using the Tooth Masseuse for 20 minutes per day for the early resolution of crowding or the alleviation of pain.

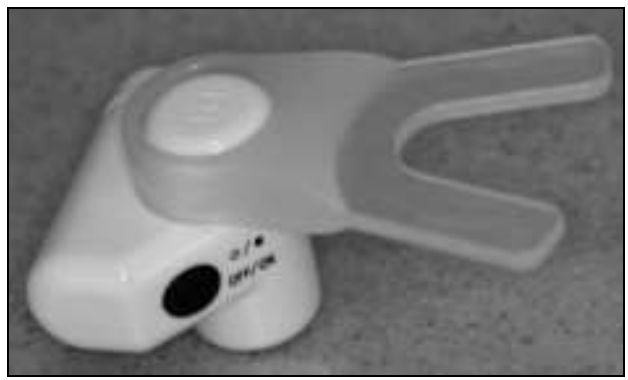

Fig 2: Tooth masseuse

\section{VPro5 device}

It is manufactured by VPro5, Propel Orthodontics, Ossining, New York. It is used for applying a vibrational frequency of $120 \mathrm{~Hz}$ for $5 \mathrm{~min} /$ day ${ }^{[8]}$.

A randomized controlled trial conducted by Alansari et al. ${ }^{[8]}$ to assess the efficacy of this device showed that time intervals between aligners were significantly reduced by daily vibration treatment with VPro 5 device.

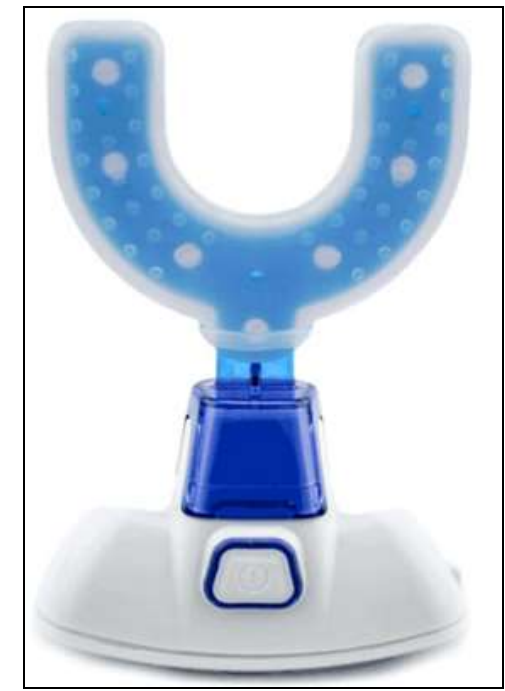

Fig 3: VPro5 device

\section{Electrical toothbrushes}

Another alternative device for providing vibration therapy are the electrical toothbrushes. Following electrical toothbrushes can be used for this purpose

- Electrical toothbrushes (Hamming Bird, Oral B, Braun, P\&G company, Cincinnati, Ohio, USA)- $113 \mathrm{~Hz}$ for 10min/day (RCT by Liao et al. ${ }^{[9]}$ They were considered clinically beneficial)

- Electrical toothbrushes (Colgate Motion-Multi Action, Colgate-Palmolive Company, New York, USA)- $125 \mathrm{~Hz}$ for $15 \mathrm{~min} /$ day (RCT by Leethanakul et al. ${ }^{[10]}$ Vibratory stimuli increased tooth movement)

- Electrical toothbrushes (Oral-B Triumph, OD17; P\&G company, Cincinnati, Ohio, USA)- $125 \mathrm{~Hz}$ for $20 \mathrm{~min} /$ day (RCT by Azeem et al. ${ }^{[1]}$ Vibrations generated did not accelerate tooth movement)

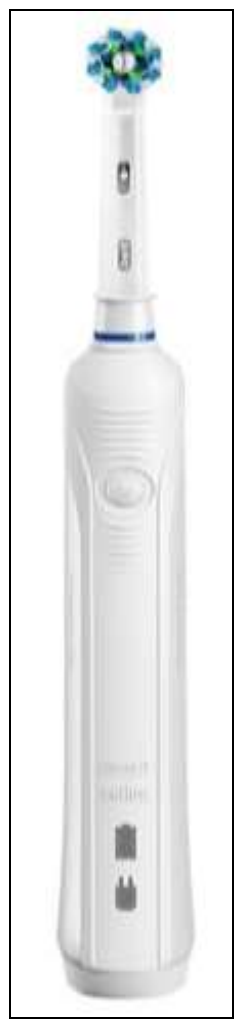

Fig 4: Electrical toothbrushes

\section{Vibration to accelerate orthodontic tooth movement}

Accelerated orthodontics and vibration therapy to fast track orthodontic tooth movement (OTM) are among the highly debated topics in the orthodontics in recent years. Jeremy Mao was the inventor of the concept behind vibrating force to enhance and accelerate tooth movement ${ }^{[12]}$. In a monkey model, tooth movement rates up to $40 \%$ faster were demonstrated in response to vibration as early as 1986 by Shimizu et al. ${ }^{[13]}$

H. Utomo (Airlangga University) has suggested via literature search that patients who regularly chews gum (a crude form of vibratory force application) exhibit accelerated rates of tooth movement. It is believed that orthodontic tooth movement is accompanied by "site-specific" alveolar bone remodelling \& is essential for tooth movement ${ }^{[14]}$. It is characterized by tandem periods of osteoclastic recruitment, bone resorption, reversal and bone formation ${ }^{[15]}$. A study by Davidovitch et al. ${ }^{[16]}$ results suggests that electric stimulation enhances cellular enzymatic phosphorylation activities in periodontal tissues and may be a potent tool in accelerating 
alveolar bone turnover. Davidovitch et al. [16] suggested orthodontic tooth movement may be accelerated by the use of locally applied electric currents. The rate of movement as well as the total movement was found to be greater with the pulsed tooth than in the control tooth with the rate of movement being two-fold higher at times. Nishimura et al. ${ }^{[17]}$ showed vibratory stimulation could accelerate the rate of tooth movement, with no collateral damage to periodontal tissue. The same study revealed that receptor activator of the NF kappa-B and ligand (RANK/RANKL) signaling pathway, which contributes to osteoclast formation, was activated in response to vibration.

A study in humans showed vibratory stimuli provided no clinical advantage for early resolution of crowding or alleviation of pain during initial alignment ${ }^{[7]}$. In contrast, a number of studies have reported that short durations of lowmagnitude, high-frequency resonance vibration combined with orthodontic force can increase the rate of orthodontic tooth movement without additional tissue damage in humans $[18,19]$

Various surgical and non surgical methods have been introduced to accelerate orthodontic tooth movement but vibrations are an easy to apply technique which can be used to reduce overall treatment time in orthodontics.

\section{Vibration to control pain during orthodontic treatment}

Pain following orthodontic treatment has been reported to be quite prevalent and may affect patient compliance with treatment ${ }^{[20]}$. It is a complex phenomenon involving multiple variants and is influenced by factors such as age, gender, individual pain threshold, and amount of force applied. The usual method of dealing with discomfort is with the use of analgesics. NSAIDS have been reported to decrease the rate of tooth movement and thus possibly increase orthodontic treatment times. Other alternatives to analgesics for pain control include the use of lower force levels. But even if lower force levels are used, Lim et al. ${ }^{[21]}$ showed that pain was still experienced by most patients. More recently low level laser therapy, transcutaneous electrical nerve, acupuncture, viscoelastic bite wafers, chewing gum and vibratory stimulation have been shown to be effective post orthodontic adjustment.

A device that vibrates at frequency (between $100 \mathrm{~Hz}$ and 250 $\mathrm{Hz}$ ) and at a force (approximately $100 \mathrm{~g}$ or $1 \mathrm{~N}$ ) can be used in humans for reducing pain associated with orthodontic adjustments ${ }^{[12]}$.

Vibration may help relieve compression of the PDL, promoting normal circulation to prevent the proliferation of inflammatory by-products. A study by Lobre et al. ${ }^{\text {[22] }}$ showed that the use of a micropulse vibration device significantly reduced the perception of overall and biting pain in patients undergoing orthodontic treatment.

\section{Advantages}

Following are the advantages of vibrations

- Ease of use.

- Non invasive hence readily accepted by patients.

- Decreases the overall treatment time in orthodontics.

- Decreases the pain associated with orthodontic treatment.

- Minimal side effects in comparison to other means of accelerating orthodontic tooth movement.

\section{Disadvantages}

Following are the disadvantages of vibrations

- Requirement of special equipment for use.
- Requires patient compliance.

- Must be used on a regular basis for appropriate results.

- It cannot be used alone. Should be combined with an orthodontic therapy such as braces or clear aligners.

\section{Future scope}

Vibration in orthodontics is still in its infancy. Initial studies have shown vibrations to be effective in increasing the rate of tooth movement. More clinical studies and research are required to completely study the use of vibrations in orthodontics ${ }^{[23]}$

\section{Conclusion}

It can be concluded that compared to invasive methods to accelerate orthodontic tooth movement such as corticotomy or microperforations, using mechanical vibrations could prove to be a much safer and comfortable alternative but in relation to various articles reviewed, the efficacy of vibration therapy is still inconclusive and thus more studies are needed to confirm the benefits of this approach which in turn can prove to be a boon in the context of accelerating tooth movement and minimizing the pain during orthodontic treatment.

\section{References}

1. Shah A. Use of Vibration in Orthodontics-A Review. IJARnD. 2017;2(1).

2. Kneale J. Dr Granville's Thunderbolt: Drink and the public in the life of one nineteenth-century doctor. SHAD. 2014;28(2):120-42.

3. Shapiro E, Roeber F, Klempner L. Pulsating forces in orthodontics. Am J Orthod Dentofacial Orthop. 1981;79(3):348.

4. Woodhouse NR, DiBiase AT, Johnson N, Slipper C, Grant J, Alsaleh M et al. Supplemental vibrational force during orthodontic alignment: a randomized trial. JDR 2015;94(5):682-9.

5. Yadav S, Dobie T, Assefnia A, Gupta H, Kalajzic Z, Nanda R. Effect of low-frequency mechanical vibration on orthodontic tooth movement. Am J Orthod Dentofacial Orthop 2015;148(3):440-9.

6. Alikhani M, Alansari S, Hamidaddin MA, Sangsuwon C, Alyami B, Thirumoorthy SN et al. Vibration paradox in orthodontics: Anabolic and catabolic effects. PLoS One 2018;13(5):123-7.

7. Miles P, Smith H, Weyant R, Rinchuse DJ. The effects of a vibrational appliance on tooth movement and patient discomfort: a prospective randomised clinical trial. Aust Orthod J 2012;28(2):213.

8. Alansari S, Atique MI, Gomez JP, Hamidaddin M, Thirumoorthy SN, Sangsuwon C et al. The effects of brief daily vibration on clear aligner orthodontic treatment. J World Fed Orthod 2018;7:134-40.

9. Liao Z, Elekdag-Turk S, Turk T, Grove J, Dalci O, Chen $\mathrm{J}$ et al. Computational and clinical investigation on the role of mechanical vibration on orthodontic tooth movement. J Biomech 2017;60:57-64.

10. Leethanakul C, Suamphan S, Jitpukdeebodintra S, Thongudomporn U, Charoemratrote C. Vibratory stimulation increases interleukin-1 beta secretion during orthodontic tooth movement. Angle Orthod 2016;86:7480.

11. Azeem M, Afzal A, Jawa SA, Haq AU, Khan M, Akram H. Effectiveness of electric toothbrush as vibration method on orthodontic tooth movement: A split-mouth study. Dental Press J Orthod 2019;24:49-55. 
12. Goyal V, Singh RK, Gupta N, Singh G, Relhan A. Role of Vibrations in Orthodontics: A Review. Orthod J Nepal 2018;8(2):50-4.

13. Turner CH, Robling AG. Mechanisms by which exercise improves bone strength. J bone Metab 2005;23:16-22.

14. Kopher RA, Mao JJ. Suture growth modulated by the oscillatory component of micromechanical strain. J Bone Miner Res 2003;18(3):521-8.

15. Rubin CT, Donahue HJ, Rubin JE, McLeod KJ. Optimization of electric field parameters for the control of bone remodeling: exploitation of an indigenous mechanism for the prevention of osteopenia. $\mathbf{J}$ Bone Miner Res 1993, 8.

16. Davidovitch Z, Finkelson MD, Steigman S, Shanfeld JL, Montgomery PC, Korostoff E. Electric currents, bone remodeling, and orthodontic tooth movement: II. Increase in rate of tooth movement and periodontal cyclic nucleotide levels by combined force and electric current. Am J Orthod 1980;77(1):33-47.

17. Nishimura M, Chiba M, Ohashi T, Sato M, Shimizu Y, Igarashi $\mathrm{K}$ et al. Periodontal tissue activation by vibration: intermittent stimulation by resonance vibration accelerates experimental tooth movement in rats. Am J Orthod Dentofacial Orthop 2008;133(4):572-83.

18. Kau CH, Nguyen JT, English JD. The clinical evaluation of a novel cyclical force generating device in orthodontics. Orthod Pract 2010;1:1-4.

19. Kau Chung H. A radiographic analysis of tooth morphology following the use of a novel cyclical force device in orthodontics. Head Face Med. 2011;7(1-5):7-14

20. Krukemeyer AM, Arruda AO, Inglehart MR. Pain and orthodontic treatment: patient experiences and provider assessments. Angle Orthod 2009;79(6):1175-81.

21. Lim HM, Lew KK, Tay DK. A clinical investigation of the efficacy of low level laser therapy in reducing orthodontic postadjustment pain. Am J Orthod Dentofacial Orthop 1995;108:614-22.

22. Lobre WD, Callegari BJ, Gardner G, Marsh CM, Bush AC, Dunn WJ. Pain control in orthodontics using a micropulse vibration device: A randomized clinical trial. Angle Orthod 2016;86(4):625-30.

23. Darak R, Fulsundar P. Cyclic loading- Accelerating orthodontic treatment. Indian J Appl Res 2019;9(2):5-7. 